\title{
The Reliability of Assessment of Ki-67 Expression on Core Needle Biopsy and the Surgical Specimens of Invasive Breast Cancer: Comparison of Local Pathologists' Assessment and Central Review ${ }^{*}$
}

\author{
Yoshio Mizuno ${ }^{1}$, Tsuneo Natori ${ }^{2}$, Naoko Takeda ${ }^{1,3}$, Junichi Yamada $^{4}$, Hiroaki Abe $^{4}$, Yuko Inoue $^{3}$, \\ Hiroshi Seto ${ }^{5}$, Kazuhiko Sato ${ }^{1}$ \\ ${ }^{1}$ Department of Breast Oncology, Tokyo-West Tokushukai Hospital, Tokyo, Japan; ${ }^{2}$ Clinical Testing Business, Testing Division, \\ Special Reference Laboratories, Inc., Tokyo, Japan; ${ }^{3}$ Inoue Ladies Clinic, Tokyo, Japan; ${ }^{4}$ Department of Clinical Pathology, To- \\ kyo-West Tokushukai Hospital, Tokyo, Japan; ${ }^{5}$ Seto Hospital, Saitama, Japan. \\ Email: yoshio.mizuno@tokushukai.jp
}

Received August 28 $8^{\text {th }}, 2012$; revised September $30^{\text {th }}, 2012$; accepted October $9^{\text {th }}, 2012$

\begin{abstract}
Purpose: The aim of this study was to assess the reliability of Ki-67 expression on core needle biopsy $(\mathrm{CNB})$ and the surgical specimens of invasive breast cancer. We examined the concordance rate of Ki-67 expressions, hormone receptors, and human epidermal growth factor receptor 2 (HER2) status from a CNB with from a surgery in invasive breast cancer. Methods: A retrospective study was conducted on a clinical database of patients who underwent surgery for early breast cancer. Of these, 193 patients who underwent CNB before the surgery were enrolled. A cut-off value of $20 \%$ was used for Ki-67-positive criteria. Expression of estrogen receptor (ER), progesterone receptor (PgR), and HER2 were examined and compared with that of Ki-67. To evaluate discordance between the pathologists' earlier assessments, we re-examined Ki-67 expression among the Ki-67 discordant group in a central laboratory. Results: The concordance rate for Ki-67 expression between the two specimen types was $77.7 \%$, which was significantly lower than that for ER, PgR, and HER2 expression $(95.9 \%, 88.1 \%$, and $91.6 \%$, respectively). The concordance rate for re-examined $\mathrm{Ki}-67$ expression among the Ki-67 discordant group improved to $93.8 \%$ and was not significantly different from that for the other receptors. Conclusion: The concordance rate for Ki-67 expression between biopsy and surgical specimens was significantly lower than that for ER, PgR, and HER2 expressions, but re-examination of Ki-67 expression in a central laboratory revealed no significant difference among the receptors, suggesting the need for standard pathological assessment of $\mathrm{Ki}-67$ expression for clinical use as a predictive marker of breast cancer.
\end{abstract}

Keywords: Ki-67; CNB; Concordance Rate; Standard Assessment

\section{Introduction}

In recent years, focus has been placed on the usefulness of preoperative endocrine therapy for postmenopausal hormone-receptor-positive breast cancer, patients with the aim of improving breast conservation rates and selecting patients with high susceptibility to endocrine therapy [1-3].

Certain biomarkers provide clinically useful prognostic and predictive information in preoperative endocrine therapy. To identify alternative post-treatment factors that predict recurrence-free survival after preoperative endocrine therapy, Dowsett et al. examined changes in the $\mathrm{Ki}-67$ index before and after 2 weeks of preoperative

\footnotetext{
This study was not funded by any public or private grant.

\#All authors declare no conflict of interest.
}

endocrine therapy, and found that patients with higher Ki67 expression after 2 weeks of preoperative endocrine therapy had significantly lower recurrence-free survival [4-5]. In multivariable analysis, Ellis et al. recently demonstrated that among 228 postmenopausal women with ER-positive breast cancer who received preoperative endocrine therapy, 4 factors-pathological tumor size, node status, ER status, and the Ki-67 index - were determined to predict long-term outcomes after completion of preoperative endocrine therapy [6].

Based on this, considering pretreatment histopathological findings obtained using core needle biopsy (CNB) and biological markers are important for determining a therapeutic strategy. In addition, variations in the pre- and post-treatment using the Ki-67 index are reported to be related to preoperative hormone therapy as 
a predictor of prognosis and effect [4-8]. Variations in the Ki-67 index are evaluated using CNB specimens before treatment and using surgical specimens after treatment. On the other hand, it is important to consider that there may be discrepancies in the Ki-67 index between the CNB and surgical specimens, even though preoperative treatment is not performed.

Consequently, to ascertain the necessity for standardizing $\mathrm{Ki}-67$ index measurement methods in preoperative hormone therapy, we evaluated the Ki-67 index concordance rates between preoperative $\mathrm{CNB}$ and surgical specimens. Furthermore, we re-examined the discordance cases in the Ki-67 index through central review, in addition to comparing the concordance rates in the expression of other biological markers.

\section{Patients and Materials}

We retrospectively analyzed data from patients who underwent primary surgery for early breast cancer at Tokyo-West Tokushukai Hospital from August, 2008 to October, 2011. Of these, 193 consecutive patients who received CNB before surgery were enrolled. We retrospectively analyzed data from patients who underwent primary surgery for early breast cancer at Tokyo-West Tokushukai Hospital from August, 2008 to October, 2011. Of these, 193 consecutive patients who received core needle biopsies (CNB) before surgery were enrolled. The inclusion criteria included 1) diagnosis of breast cancer confirmed by CNB and 2) no evidence of metastases at initial assessment, and the exclusion criteria included 1) evidence of metastases at initial assessment; 2) inoperable tumors (stage T4, N2, or N3); 3) patients with neoadjuvant chemotherapy, and 4) patients with ductal carcinoma in situ. For CNB, a 16- or 18-gauge automated needle device with a 22-mm throw biopsy gun was used. Three or more CNB specimens were obtained per patient. CNB specimens were placed in $20 \%$ formalin for $>6$ hours to $<48$ hours. The original tumors had been fixed in buffered formalin and embedded in paraffin. One representative tissue block for each tumor was selected for routine evaluation of estrogen receptor (ER), progesterone receptor $(\mathrm{PgR})$, human epidermal growth factor receptor 2 (HER2), and Ki-67 by immunohistochemical analysis. The clone MIB-1 (Dako, Denmark) was used for immunohistochemical analysis of Ki-67.

According to our institutional ethics committee's policies, general consent is taken from all the patients who undergo medical care.

\section{Methods}

All cases were evaluated by registered local pathologists. Although many different systems for grading of patho- logical responses by local pathologists have been proposed, no standard method has been adopted. The concordance rates for assessment of ER, PgR, HER2, and Ki-67 by local pathologists were reviewed, and in cases of non-matching Ki-67, the tumor diameters (approximately indicative of tumor heterogeneity) and operative method (approximately indicative of formalin fixation condition) were studied. Next, the non-matching cases from August, 2008 to October, 2011 were reassessed by central review. The central review was performed by scanning magnification to count at least 1000 cells in the most densely labeled areas. For all non-matching cases, the percentage of tumor cells with any nuclear staining was recorded.

\section{Statistical Analysis}

Statistical significance for concordance rates between the 2 types of specimens was evaluated by Wilcoxon t-test. To evaluate the consequence of formalin and genetic heterogeneity, parameters, such as the operative method and tumor size, were analyzed by $\chi^{2}$ analysis.

\section{Results}

The mean patient age was 56.3 years (median, 55.5 years; range, 30 - 91 years).

Seventy-three patients ultimately underwent mastectomy and the remainder underwent breast-conserving surgery.

For ER, 152 cases showed positive and 33 cases showed negative findings for both $\mathrm{CNB}$ and surgical specimens; 3 cases showed positive findings for CNB specimens and negative findings for surgical specimens; and 5 cases showed negative findings for CNB specimens and positive findings for surgical specimens. For PgR, 111 cases showed positive findings for CNB and surgical specimens, 59 cases showed negative findings for CNB and surgical specimens, 12 cases showed positive findings for $\mathrm{CNB}$ specimens and negative findings for surgical specimens, and 11 cases showed negative findings for CNB specimens and positive findings for surgical specimens. For HER2 expression, 27 cases showed positive findings for $\mathrm{CNB}$ and surgical specimens; 137 cases showed negative findings for CNB and surgical specimens; 11 cases showed positive findings for $\mathrm{CNB}$ specimens and negative findings for surgical specimens; and 4 cases showed negative findings for CNB specimens and positive findings for surgical specimens. For Ki-67, 85 cases showed positive findings for CNB and surgical specimens; 65 cases showed negative findings for $\mathrm{CNB}$ and surgical specimens; 28 cases showed positive findings for CNB specimens and negative findings for surgical specimens; and 15 cases 
showed negative findings for CNB specimens and positive findings for surgical specimens. Concordance between CNB and surgical specimens for marker expression is shown in Tables 1-4. In our series, the concordance rate for $\mathrm{Ki}-67$ expression between the two specimen types was $77.7 \%$, significantly lower than that for ER, PgR, and HER2 expression $(95.9 \%, 88.1 \%$, and 91.6\%, respectively) (Table 5).

Table 1. Concordance rate between CNB and surgical specimens for ER status.

\begin{tabular}{ccc}
\hline & $\begin{array}{c}\text { Positive surgical } \\
\text { specimen }\end{array}$ & $\begin{array}{c}\text { Negative surgical } \\
\text { specimen }\end{array}$ \\
\hline Positive (CNB) & 152 & 3 \\
Negative (CNB) & 5 & 33 \\
\hline
\end{tabular}

Concordance rate for ER: $95.9 \%$.

Table 2. Concordance rate between CNB and surgical specimens for PgR status.

\begin{tabular}{ccc}
\hline & $\begin{array}{c}\text { Positive surgical } \\
\text { specimen }\end{array}$ & $\begin{array}{c}\text { Negative surgical } \\
\text { specimen }\end{array}$ \\
\hline Positive $(\mathrm{CNB})$ & 111 & 12 \\
Negative $(\mathrm{CNB})$ & 11 & 59 \\
\hline
\end{tabular}

Concordance rate for PgR: $88.1 \%$.

Table 3 Concordance rate between CNB and surgical specimen for HER2 status.

\begin{tabular}{ccc}
\hline & $\begin{array}{c}\text { Positive surgical } \\
\text { specimen }\end{array}$ & $\begin{array}{c}\text { Negative surgical } \\
\text { specimen }\end{array}$ \\
\hline Positive (CNB) & 27 & 11 \\
Negative (CNB) & 4 & 137 \\
\hline
\end{tabular}

Concordance rate for HER2: $91.6 \%$.

Table 4. Concordance rate between CNB and surgical specimen for Ki-67 expression.

\begin{tabular}{ccc}
\hline & $\begin{array}{c}\text { Positive } \\
\text { (surgical specimen) }\end{array}$ & $\begin{array}{c}\text { Negative } \\
\text { (surgical specimen) }\end{array}$ \\
\hline Positive (CNB) & 85 & 28 \\
Negative (CNB) & 15 & 65 \\
\hline
\end{tabular}

Concordance rate for Ki-67: 77.7\%.

Table 5. Comparison of concordance rates between ER, PgR, and HER2 with that of Ki-67.

\begin{tabular}{ccc}
\hline & Concordance rate & $\begin{array}{c}\text { Comparison of concordance } \\
\text { rates with Ki-67 }\end{array}$ \\
\hline ER & $95.9 \%$ & $P<0.01$ \\
PgR & $88.1 \%$ & $P<0.01$ \\
HER2 & $91.6 \%$ & $P<0.01$ \\
Ki-67 & $77.7 \%$ & - \\
\hline
\end{tabular}

Analysis of the operative methods used among the 151 concordant cases showed that breast-conserving surgery was performed in 94 cases $(62.3 \%)$ and mastectomy in 57 cases $(37.7 \%)$. No significant difference in parameters, such as operative method (mastectomy vs. breast-conserving surgery), were observed between the two patient groups (Table 6).

Analysis of tumor size among the 151 concordant cases showed that pT1 tumor occurred in 92 cases and pT2 tumor in 59 cases. No significant difference in parameters, such as tumor size (pT1 vs. $\geq$ pT2) was observed between the two patient groups (Table 7).

The central laboratory re-examination of Ki-67 expression among the Ki-67 discordant group cases showed that 30 of the 43 non-matching cases should have been placed in the concordant group. The concordance rate for Ki-67 after re-examination by the central review improved to $93.8 \%$ (Table 8 ).

\section{Discussion}

The Ki-67 index is a crucial factor as a predictor of therapeutic effect and prognosis in preoperative hormone therapy [9-12]. There are, however, certain identified problems with regard to the $\mathrm{Ki}-67$ index including standardization of measuring method, reproducibility of

Table 6. No significant difference between operative methods.

\begin{tabular}{lccc}
\hline & Breast-conserving Surgery & Mastectomy & $\mathrm{N}$ \\
\hline Concordance & 94 cases $(62.3 \%)$ & $57(37.7 \%)$ & 151 \\
Discordance & $26(61.9 \%)$ & $16(38.1 \%)$ & 42 \\
\hline
\end{tabular}

Table 7. No significant difference between tumor size $<$ pT1 and $\geq$ pT 2 .

\begin{tabular}{cccc}
\hline & $<\mathrm{pT} 1$ & $\geq \mathrm{pT} 2$ & $\mathrm{n}$ \\
\hline Concordance & $92 \operatorname{cases}(60.9 \%)$ & $59(39.1 \%)$ & 151 \\
Discordance & $29(69.0 \%)$ & $13(31.0 \%)$ & 42 \\
\hline
\end{tabular}

Table 8. Comparison of concordance rates between ER, PgR, and HER2 with that of Ki-67 (central review).

\begin{tabular}{ccc}
\hline & Concordance rate & $\begin{array}{c}\text { Comparison of concordance rates } \\
\text { with Ki-67 (central review) }\end{array}$ \\
\hline ER & $95.9 \%$ & $P=0.42$ \\
PgR & $88.1 \%$ & $P=0.02$ \\
HER2 & $91.6 \%$ & $P=0.08$ \\
Ki-67 & $77.7 \%$ & - \\
\hline
\end{tabular}


measurement results, and establishment of cutoff values [13-16].

Matthew et al. evaluated 209 breast cancer patients using concordance rates between biological markers in needle biopsy and surgical specimens. Their report indicates that concordance rates of Ki-67, ER, PgR, HER2, tumor grade, mitotic rate were $59 \%, 88 \%, 78 \%, 81 \%$, $59 \%$, and $61 \%$, respectively; and the concordance rates of Ki-67, PgR, HER2, tumor grade, and mitotic rate were lower than that of ER [17].

The current investigation indicated that the concordance rate of $\mathrm{Ki}-67$ expression in $\mathrm{CNB}$ and surgical specimens was $77.7 \%$, significantly lower than those of ER (95.9\%), PgR (88.1\%), and HER2 (91.6\%). The following factors were thought to cause discordance: 1) tumor heterogeneity, 2) differences in formalin fixation conditions, and 3) a lack of standardization of the measuring method by pathologists. Although the concordance rates between tumor diameter and its equivalence to tumor heterogeneity, as well as Ki-67 expression were compared to determine the effect on tumor heterogeneity, no significant correlation was observed. Further, although the concordance rates between the operative method and its equivalence to formalin fixation conditions as well as $\mathrm{Ki}-67$ expression were compared to consider the effect on formalin fixation, no significant correlation was observed. In order to consider the lack of standardization of the measurement method by pathologists, we reexamined the discordant cases in the Ki-67 index through central review.

In reexamination through central review, the concordance rate of $\mathrm{Ki}-67$ expression was $93.8 \%$, which was almost equivalent to that of ER, PgR, and HER2. Ki-67 measurements were examined microscopically by the pathologists; the percentage of positive cells to total tumor cells was calculated and this was reported as the Ki-67 labeling index. Because the pathologists used visual judgment, there was some discordance reported between the pathologists in the percentage of positive cells. Finally, because the concordance rate of Ki-67 expression was almost equivalent to that of ER, PgR, and HER2 in our reexamination through central review, it was suggested that standardization of the measurement method by pathologists is important.

In order to ascertain the necessity of whether the methods to measure the Ki-67 index should be standardized in preoperative hormone therapy, we evaluated the index concordance rates between preoperative $\mathrm{CNB}$ and surgical specimens, and reexamined the discordance cases in the Ki-67 index through central review. In CNB and surgical specimens, the concordance rate of $\mathrm{Ki}-67$ was lower than that of other biological markers. However, in the reexamination through central review, the concor- dance rate of $\mathrm{Ki}-67$ was almost the same as that of other biological markers. Therefore, for the clinical application of $\mathrm{Ki}-67$, it is necessary to standardize the methods to measure Ki-67 index.

\section{Acknowledgements}

The authors would like to thank Enago (www.enago.jp) for the English language review. This study was presented in part at the 34th Annual San Antonio Breast Cancer Symposium (poster).

\section{REFERENCES}

[1] J. S. Chawla, C. X. Ma and M. J. Ellis, "Neoadjuvant Endocrine Therapy for Breast Cancer," Surgical Oncology Clinics of North America, Vol. 19, No. 3, 2010, pp. 627 638. doi:10.1016/j.soc.2010.04.004

[2] J. A. Olson Jr., G. T. Budd, L. A. Carey, L. A. Harris, L. J. Esserman, G. F. Fleming, P. K. Marcom, G. S. Leight Jr., T. Giuntoli, P. Commean, K. Bae, J. Luo and M. J. Ellis, "Improved Surgical Outcomes for Breast Cancer Patients Receiving Neoadjuvant Aromatase Inhibitor Therapy: Results from a Multicenter Phase II Trial," Journal of the American College of Surgeons, Vol. 208, No. 5, 2009, pp. 906-914, Discussion 915-916. doi:10.1016/j.jamcollsurg.2009.01.035

[3] Y. H. Chia, M. J. Ellis and C. X. Ma, "Neoadjuvant En-docrine Therapy in Primary Breast Cancer: Indications and Use as a Research Tool," British Journal of Cancer, Vol. 103, No. 6, 2010, pp. 759-764. doi:10.1038/sj.bjc. 6605845

[4] M. Dowsett, S. R. Ebbs, J. M. Dixon, A. Skene, C. Grif-fith, I. Boeddinghaus, J. Salter, S. Detre, M. Hills, S. Ash-ley, S. Francis, G. Walsh and I. E. Smith, "Biomarker Changes during Neoadjuvantanastrozole, Tamoxifen, or the Combination: Influence of Hormonal Status and HER-2 in Breast Cancer-A Study from the IMPACT Trialists," Journal of Clinical Oncology, Vol. 23, No. 11, 2005, pp. 2477-2492. doi:10.1200/JCO.2005.07.559

[5] M. Dowsett, I. E. Smith, S. R. Ebbs, J. M. Dixon, A. Skene, R. A'Hern, J. Salter, S. Detre, M. Hills and G. Walsh, "IMPACT Trialists Group, "Prognostic Value of Ki67 Expression after Short-Term Presurgical Endocrine Therapy for Primary Breast Cancer," Journal of the National Cancer Institute, Vol. 99, No. 2, 2007, pp. 167-170. doi:10.1093/jnci/djk020

[6] M. J. Ellis, Y. Tao, J. Luo, R. A’Hern, D. B. Evans, A. S. Bhatnagar, R. H. A. Chaudri, A. von Kameke, W. R. Miller, I. Smith, W. Eiermann and M. Dowsett, "Outcome Prediction for Estrogen Receptor-Positive Breast Cancer Based on Postneoadjuvant Endocrine Therapy Tumor Characteristics," Journal of the National Cancer Institute, Vol. 100, No. 19, 2008, pp. 1380-1388. doi:10.1093/jnci/djn309

[7] M. J. Ellis, V. J. Suman, J. Hoog, L. Lin, J. Snider, A. Prat, J. S. Parker, J. Luo, K. DeSchryver, D. C. Allred, L. 
J. Esserman, G. W. Unzeitig, J. Margenthaler, G. V. Ba-biera, P. K. Marcom, J. M. Guenther, M. A. Watson, M. Leitch, K. Hunt and J. A. Olson, "Randomized Phase II Neoadjuvant Comparison between Letrozole, Anastrozole, and Exemestane for Postmenopausal Women with Estro-gen Receptor-Rich Stage 2 to 3 Breast Cancer: Clinical and Biomarker Outcomes and Predictive Value of the Baseline PAM50-Based Intrinsic SubtypeACOSOG Z1031," Journal of Clinical Oncology, Vol. 29, No. 17, 2011, pp. 2342-2349. doi:10.1200/JCO.2010.31.6950

[8] M. J. Ellis and C. Ma, "Letrozole in the Neoadjuvant Setting: The P024 Trial," Breast Cancer Research and Treatment, Vol. 105, Suppl. 1, 2007, pp. 33-43. doi:10.1007/s10549-007-9701-X

[9] C X. Ma, C. G. Sanchez and M. J. Ellis, "Predicting En-docrine Therapy Responsiveness in Breast Cancer," Oncology, Vol. 23, No. 2, 2009, pp. 133-142.

[10] M. Dowsett, I. E. Smith, S. R. Ebbs, J. M. Dixon, A. Skene, C. Griffith, I. Boeddinghaus, J. Salter, S. Detre, M Hills, S. Ashley, S. Francis, G. Walsh and R. A'Hern, "Proliferation and Apoptosis as Markers of Benefit in Neoadjuvant Endocrine Therapy of Breast Cancer," Clinical Cancer Research, Vol. 12, Part 2, 2006, pp. 1024s1030s. doi:10.1158/1078-0432.CCR-05-2127

[11] M. J. Ellis, W. R. Miller, Y. Tao, D. B. Evans, R. H. A. Chaudri, Y. Miki, T. Suzuki and H. Sasano, "Aromatase Expression and Outcomes in the P024 Neoadjuvant En-docrine Therapy Trial," Breast Cancer Research and Treatment, Vol. 116, No. 2, 2009, pp. 371-378. doi:10.1007/s10549-008-0161-8

[12] M. Toi, H. Sasano and M. J. Ellis, "Future Prospects of Neoadjuvant Endocrine Therapy in Postmenopausal Breast Cancer," Japanese Journal of Cancer and Chemotherapy, Vol. 36, No. 6, 2009, pp. 1035-1042.
[13] M. Dowsett, T. O. Nielsen, R. A’Hern, J. Bartlett, R. C. Coombes, J. Cuzick, M. Ellis, N. L. Henry, J. C. Hugh, T. Lively, L. McShane, S. Paik, F. Penault-Llorca, L. Prud-kin, M. Regan, J. Salter, C. Sotiriou, I. E. Smith, G. Viale, J. A. Zujewski and D. F. Hayes, "Assessment of Ki67 in Breast Cancer: Recommendations from the International Ki67 in Breast Cancer Working Group," Journal of the National Cancer Institute, Vol. 103, No. 22, 2011, pp. 1656-1664. doi:10.1093/jnci/djr393

[14] E. Luporsi, F. André, F. Spyratos, P. M. Martin, J. Jacquemier, F. Penault-Llorca, N. Tubiana-Mathieu, B. Sigal-Zafrani, L. Arnould, A. Gompel, C. Egele, B. Poulet, K B. Clough, H. Crouet, A. Fourquet, J. P. Lefranc, C. Mathelin, N. Rouyer, D. Serin, M. Spielmann, M. Haugh, M. P. Chenard, E. Brain, P. de Cremoux and J. P. Bellocq, "Ki-67: Level of Evidence and Methodological Consid-erations for Its Role in the Clinical Management of Breast Cancer: Analytical and Critical Review," Breast Cancer Research and Treatment, Vol. 132, No. 3, 2012, pp. 895-915. doi:10.1007/s10549-011-1837-z

[15] R. Yerushalmi, R. Woods, P. M. Ravdin, M. M. Hayes and K. A. Gelmon, "Ki67 in Breast Cancer: Prognostic and Predictive Potential," The Lancet Oncology, Vol. 11, No. 2, 2010, pp. 174-183. doi:10.1016/S1470-2045(09)70262-1

[16] M. T. Weigel and M. Dowsett, "Current and Emerging Biomarkers in Breast Cancer: Prognosis and Prediction," Endocrine-Related Cancer, Vol. 17, 4, 2010, pp. R245R262. doi:10.1677/ERC-10-0136

[17] M. Ough, J. Velasco and T. J. Hieken, "A Comparative Analysis of Core Needle Biopsy and Final Excision for Breast Cancer: Histology and Marker Expression," The American Journal of Surgery, Vol. 201, No. 5, 2011, pp. pp. 692-694. doi:10.1016/j.amjsurg.2010.02.015 